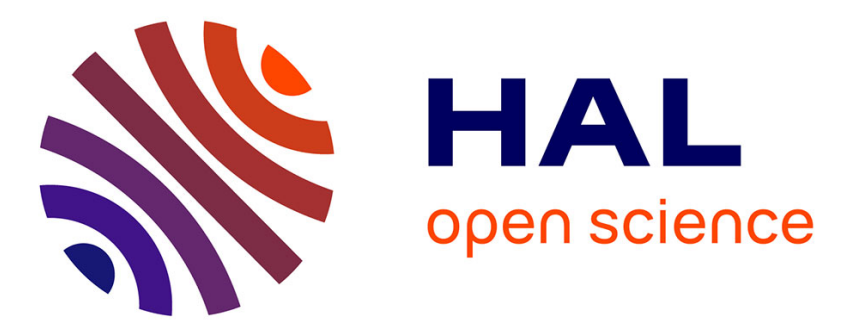

\title{
Disentangling conscious from unconscious cognitive processing with event-related EEG potentials
}

Benjamin Rohaut, Lionel Naccache

\section{To cite this version:}

Benjamin Rohaut, Lionel Naccache. Disentangling conscious from unconscious cognitive processing with event-related EEG potentials. Revue Neurologique, 2017, 10.1016/j.neurol.2017.08.001 . hal01580615

\section{HAL Id: hal-01580615 https://hal.sorbonne-universite.fr/hal-01580615}

Submitted on 1 Sep 2017

HAL is a multi-disciplinary open access archive for the deposit and dissemination of scientific research documents, whether they are published or not. The documents may come from teaching and research institutions in France or abroad, or from public or private research centers.
L'archive ouverte pluridisciplinaire HAL, est destinée au dépôt et à la diffusion de documents scientifiques de niveau recherche, publiés ou non, émanant des établissements d'enseignement et de recherche français ou étrangers, des laboratoires publics ou privés. 


\title{
Disentangling conscious from unconscious cognitive
}

\section{processing with event-related EEG potentials}

\author{
Benjamin Rohaut (1) \& Lionel Naccache $(2,3,4,5)$
}

1. Division of Critical Care \& Hospitalist Neurology, Columbia University, New York, NY, USA

2. INSERM, U 1127, F-75013, Paris, France

3. Institut du Cerveau et de la Moelle épinière, ICM, PICNIC Lab, F-75013, Paris, France

4. Sorbonne Universités, UPMC Univ Paris 06, Faculté de Médecine PitiéSalpêtrière, Paris, France

5. AP-HP, Groupe hospitalier Pitié-Salpêtrière, Department of Neurophysiology, Paris, France

\section{Corresponding authors :}

\section{Dr. Benjamin Rohaut}

E-mail : benjamin.rohaut@gmx.com; Tel: (+1) 212-305-1928

Postal Address : Division of Critical Care \& Hospitalist Neurology - CUMC, 177 Fort

Washington Avenue, Milstein 8 Center room 300, New York, NY, 10032, USA

\section{Pr. Lionel Naccache}

E-mail : lionel.naccache@aphp.fr; Tel : +33 (0)1 42162226

Postal Address : Hôpital de la Salpêtriere Fédération de Neurophysiologie Clinique 47 boulevard de l'Hôpital 75013, Paris France.

Keywords: Consciousness; Consciousness Disorders; Unconscious; Semantics; ERPs; MMN; P300; N400; P600

DOI: http://dx.doi.org/10.1016/j.neurol.2017.08.001 


\section{Abstract}

By looking for properties of consciousness, cognitive neuroscience studies have dramatically enlarged the scope of unconscious cognitive processing. This emerging knowledge inspired the development of new approaches allowing clinicians to probe and disentangle conscious from unconscious cognitive processes in noncommunicating brain-injured patients both in terms of behaviour and brain activity. This information is extremely valuable in order to improve diagnosis and prognosis in such patients both at acute and chronic settings. Reciprocally, the growing observations coming from such patients suffering from disorders of consciousness provide valuable constraints to theoretical models of consciousness. In this review we chose to illustrate these recent developments by focusing on brain signals recorded with EEG at bedside in response to auditory stimuli. More precisely, we present the respective EEG markers of unconscious and conscious processing of two classes of auditory stimuli (sounds and words). We show that in both cases, conscious access to the corresponding representation (e.g.: auditory regularity and verbal semantic content) share a similar neural signature (P3b and P600/LPC) that can be distinguished from unconscious processing occurring during an earlier stage (MMN and N400). We propose a two-stage serial model of processing and discuss how unconscious and conscious signatures can be measured at bedside providing relevant information for both diagnosis and prognosis of consciousness recovery. These two examples emphasize how fruitful can be the bidirectional approach exploring cognition in healthy subjects and in brain-damaged patients. 


\section{Introduction}

During the last decades the research on consciousness has been very productive and, as a direct consequence -, enlarged dramatically the range of unconscious cognitive processing (1-4). This major conceptual change, grounded on a rich set of original empirical findings collected in normal volunteers (using visual masking or subliminal stimulus for example) and in brain-damaged unconscious patients, concerns both the representational content of unconscious processes, as well as their links with topdown executive control. Briefly, within this relatively short period, the dominant view moved from a modular (5), automatic (6) and 'stupid' unconscious, to a more heterogeneous one, able of flexibility (7) and high-level cognitive processes (8-10) sensitive to various influences including: endogenous spatio-temporal attention (1113), conscious consideration of task instructions and stimuli sets (14-16), and executive control (16-20). This recent conceptual evolution culminated in empirical reports showing that semantic attributes of symbolic stimuli (such as written words and numbers) can be processed unconsciously and can be sensitive to executive control (for a short review see (7).

However, some cognitive processes seem to require consciousness. In particular, and according the Global Neuronal Workspace theory $(2,21)$-, three properties are specifically associated with conscious processing: (i) active maintenance of mental representations in working memory; (ii) strategical processing; and (iii) spontaneous intentional behavior. Similarly, while unconscious processing may engage multiple isolated cortical areas, neural signatures of conscious processing are associated with a late and long-lasting brain activations that mobilize long-distance coherent thalamocortical networks, particularly involving bilateral prefrontal, cingulate and parietal areas. 
This framework paved the way to the exciting opportunity of exploring residual cognition in non-communicative/unconscious patients, and to probe specific markers of conscious processing in some of them. Basically, two main complementary approaches can be used : i) probing EEG signatures of conscious access to a perceptual representation (22-34); ii) probing EEG signatures of conscious state irrespective of conscious content by looking for specific patterns of spectral power, functional connectivity or complexity measures (35-40).

In this article we chose to restrict our review to EEG signatures of conscious access to external stimuli delivered in the auditory modality (see (41) for a more general review). To do so, we will present signatures of unconscious and conscious processing of these stimuli named evoked-related potentials (or ERPs), also known as late, slow or "cognitive" evoked potentials..We describe how early and localized responses (Mismatch negativity or MMN and N400) seem to index unconscious processing of sounds and verbal semantics respectively, whereas one late and brainscale event seems to index conscious access to these acoustic and semantic representations (P3b and Late positive component or LPC respectively). Notably, these two last signatures are very similar and may reflect a common general process related to conscious access, irrespective of its content.

\section{Generality about disorders of consciousness (DOC)}

Consciousness is commonly defined as a "state of full awareness of the self and one's relationship to the environment" (42). Consciousness requires wakefulness - which relies on a complex network called ARAS (activating reticular ascending system) mostly present in the brainstem and projecting diffusely to the cortex - but cannot be identified with it. Indeed, several dissociations between preserved wakefulness (or 
vigilance) and impaired consciousness (probed with subjective reports) demonstrate the difference between these two concepts. A taxonomy is therefore possible, crossing vigilance and consciousness preservation or impairment (Fig 1). Impairments of both vigilance and consciousness are to be found in comatose, general anesthesia, deep sleep. Preserved vigilance and impaired consciousness are observed in the vegetative state (VS) or during some epileptic seizures (e.g.: absence epilepsy and complex partial seizure), and maybe in some severe dementias. When examining non communicating patients free of any motor impairment (e.g.: patients distinct from locked-in syndrome patients or from severe ALS or Guillain-Barré-Strohl syndrome patients), a state richer than the VS but without univocal functional communication has been labelled as minimally conscious stare (MCS) in 2004 (43). There is a crucial need to distinguish reliably VS from MCS patients, both for diagnosis and prognosis issues. This distinction relies primarily on the clinical examination as well as on expert behavioral measures such as the ones offered by the Coma Recovery Scale Revised (43). However, this behavioral approach has been recently enriched by the use of several functional neuroimaging studies (PET, fMRI, EEG) in order to be more sensitive to preserved neural signatures of conscious processing in some of these patients. Indeed, a recent meta-analysis reported that about $15 \%$ of clinically VS patients could show correlates of conscious processing with these tools (44). One of the first illustrative breakthrough is to be found in the study by Owen and colleagues who elaborated a mental imagery task during which non-communicative patients were instructed to imagine either playing tennis or walking in their home (45). This task, which requires the combination of verbal, working memory and mental imagery skills, was thought to require conscious processing (46). A few clinically VS patients 
showed patterns of activation very similar to the ones observed in conscious controls, strongly suggesting covert conscious processing $(46,47)$.

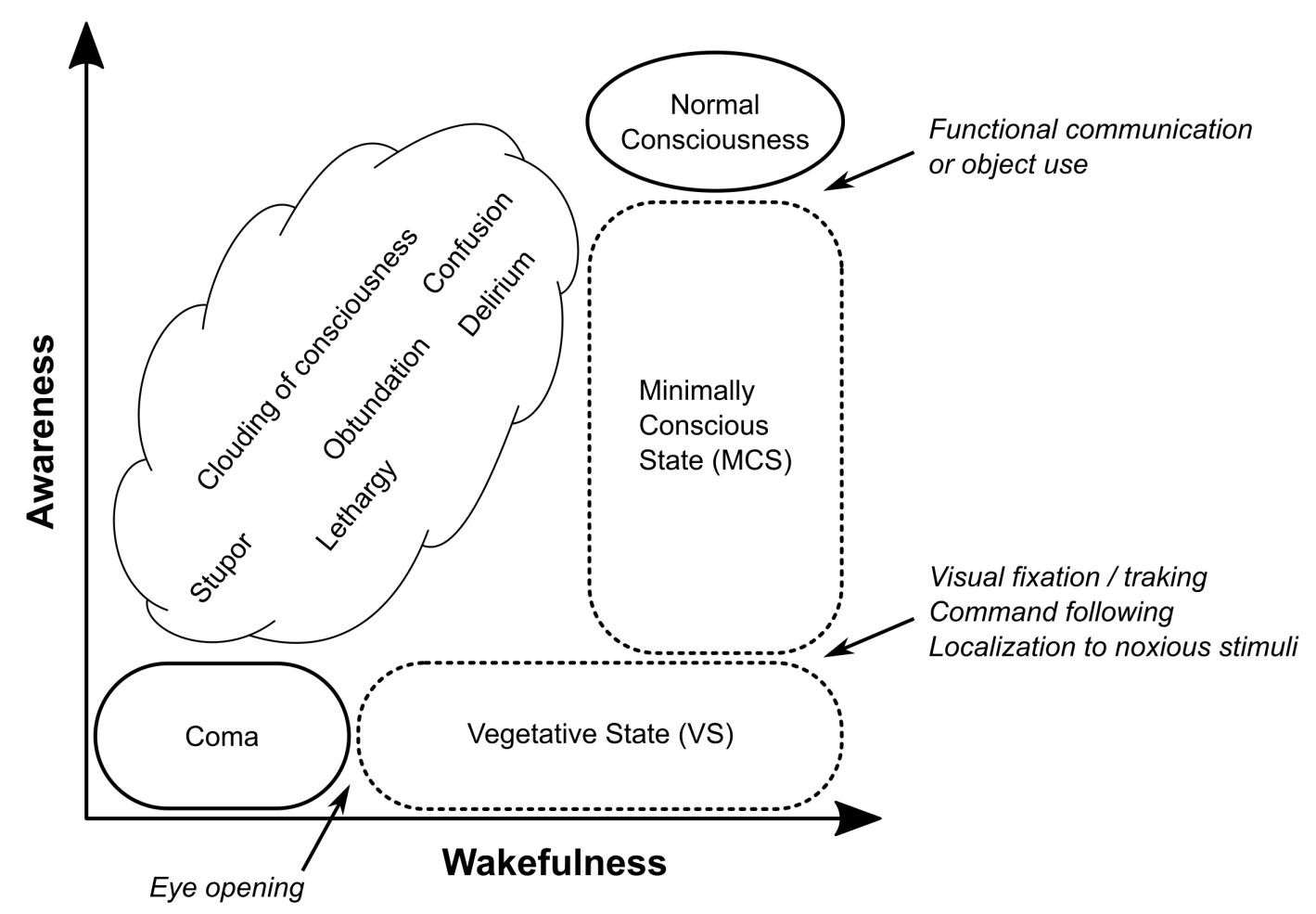

Figure 1 Schematic representation of Disorders of Consciousness according to Wakefulness and Awareness dimensions. Acute alteration of consciousness, previously described using imprecise terms such as stupor, lethargy, etc. (in the "cloud") are better described using dedicated scale such as the Glasgow Coma Scale or the FOUR-score. Coma is commonly described by a state of unresponsiveness in which the patient lies with eyes closed and cannot be aroused to respond appropriately to stimuli even with vigorous stimulation. Vegetative State (VS) and Minimally Conscious State (MCS) are mostly used to describe chronic or subacute disorders of consciousness adapted from (adapted from [86]). 


\section{Probing conscious access to external stimuli}

Once a stimulus is delivered to a conscious subject, a large and complex pattern of neural activity is usually observed. Some of these events reflect unconscious processing inaccessible to subjective report, and can be preserved during experimental conditions of unconscious perception (e.g.: subliminal perception, attentional blink, psychological refractory period, binocular rivalry, inattentional blindness, ...). Some other events are tightly related to conscious access. Obviously, the ability to disentangle between the respective correlates of unconscious and conscious processing is very important for clinicians. Actually, a large part of the clinical behavioral assessment is specifically dedicated to try to disentangle reflex (that does not require consciousness) from conscious intentional behavior. Neurophysiological monitoring of the perceptual categorization of a rare auditory deviant stimulus delivered within a serial flow of frequent standard stimuli (named the odd-ball paradigm, Fig-2a) offers a relevant step toward this goal. A rich literature demonstrates that the detection of novel auditory stimulus includes 2 distinct neural events observable on the averaged electroencephalogram (evoked potentials): an early (120-200ms) mismatch negativity response (MMN) (48) followed by a later neural response labeled P300 (witch can be split in two components: P3a and P3b) complex $(49,50)$. The respective properties of these 2 responses suggest that the MMN and the P3a mostly reflects a preattentive, unconscious response (51), whereas the late component of the P300 complex (P3b) which has been theorized as an index of working memory updating (52) is generally associated with conscious access (53). Contrarily to MMN/P3a, the P3b component has been shown to be insensitive to interstimulus intervals (54), even if it exceed several minutes (55), thus implying an active maintenance of previous stimuli in conscious working memory. In sharp 
contrast, the MMN/P3a vanishes when the interstimulus intervals exceeds a few seconds $(54,56)$, suggesting a fast decay characteristic of unconscious iconic memory $(57,58)$. In addition to this temporal distinction between MMN/P3a and P3b responses, $\mathrm{MMN} / \mathrm{P} 3 \mathrm{a}$ are largely resistant to top-down and attentional effects. They can even be observed during rapid eye-movement sleep (59) and anesthesia (60), and in unconscious comatose $(61-63)$ or vegetative state patients $(23,64)$ or in response to visual subliminal stimuli $(65,66)$, whereas the $\mathrm{P} 3 \mathrm{~b}$ is highly dependent on attention and conscious awareness of the stimulus $(53,67)$. Still, using a classical odd-ball paradigm, the MMN/P3a and the $\mathrm{P} 3 \mathrm{~b}$ are sometime very close in time and thus, could be difficult to differentiate, and it's even worth for the fine distinction between P3a and P3b. This fine analyze could be more difficult in patients whose the topographies and latencies can be modified.

To circumvent these limitations, we designed in 2009 the "Local Global" paradigm in which 2 embedded levels of auditory regularity are defined, respectively at a local (within trial, called local standard trials or LS) and at a global (across trials called global standard trials or GS) time scale (25) (in Fig 2b). To validate our paradigm, we first analyzed its brain mechanisms with high temporal and spatial resolutions by combining high-density scalp ERP, intracerebral EEG, and fMRI measurements in conscious subjects submitted to distinct experimental manipulations of their consciousness of the stimuli. The violations of the local regularity (local deviant trial or LD) elicited measurable ERPs in both conscious and nonconscious conditions (MMN and P3a named "local effect"; see contrast LS vs LD in in Fig 2d), but the violation of the global regularity (global deviant trial or GD) was detected only during conscious processing (P3b named "global effect"; see contrast GS vs GD in in Fig 2d). In other words, the presence of an ERP signature of the detection of the violation 
of the global regularity in an individual subject should be considered as a diagnostic of conscious processing of the stimuli. We then probed the scientific and clinical potential of our test by recording non communicating patients either in the vegetative state (VS) or in the minimally conscious state (MCS). While the first component ("local effect") was present in most of the patients, either in a VS or MCS, the late component "global effect" was present essentially in MCS patients. Moreover the few VS patients who showed a "global effect" improved significantly after the recording suggesting that clinical examination might have underestimate the actual cognitive patient's abilities $(27,29)$.

This paradigm is now used in several sites. Note however that in a recent study, Tzovara et al. used a multivariate decoding algorithm (and not the usual ERP method), and reported evidence for preserved processing of the global regularity in some post-cardiac arrest comatose patients (68). While this result may challenge the general value of the 'global effect' signature to probe consciousness, several important points suggest that this decoding performance was driven by an unconscious early processing (within the MMN window) we previously published (69), and not by the late and sustained (P3b) event that we proposed as the possible signature of conscious access (70). Note that such an effect is inherent to a statistical regularity difference between the physical identity of global standard (GS) and global deviant (GD) trials that modulates the early and unconscious MMN-window response. A strong finding supporting this view stems from tests of generalization of the decoding algorithm: when half of trials (LS or LD) are used to train a decoder to distinguish global standard from global deviant trials, and that this decoder is then tested on the second half of trials (LS or LD), the decoding performance in the early time window drops considerably, whereas the decoding performance of the late time 

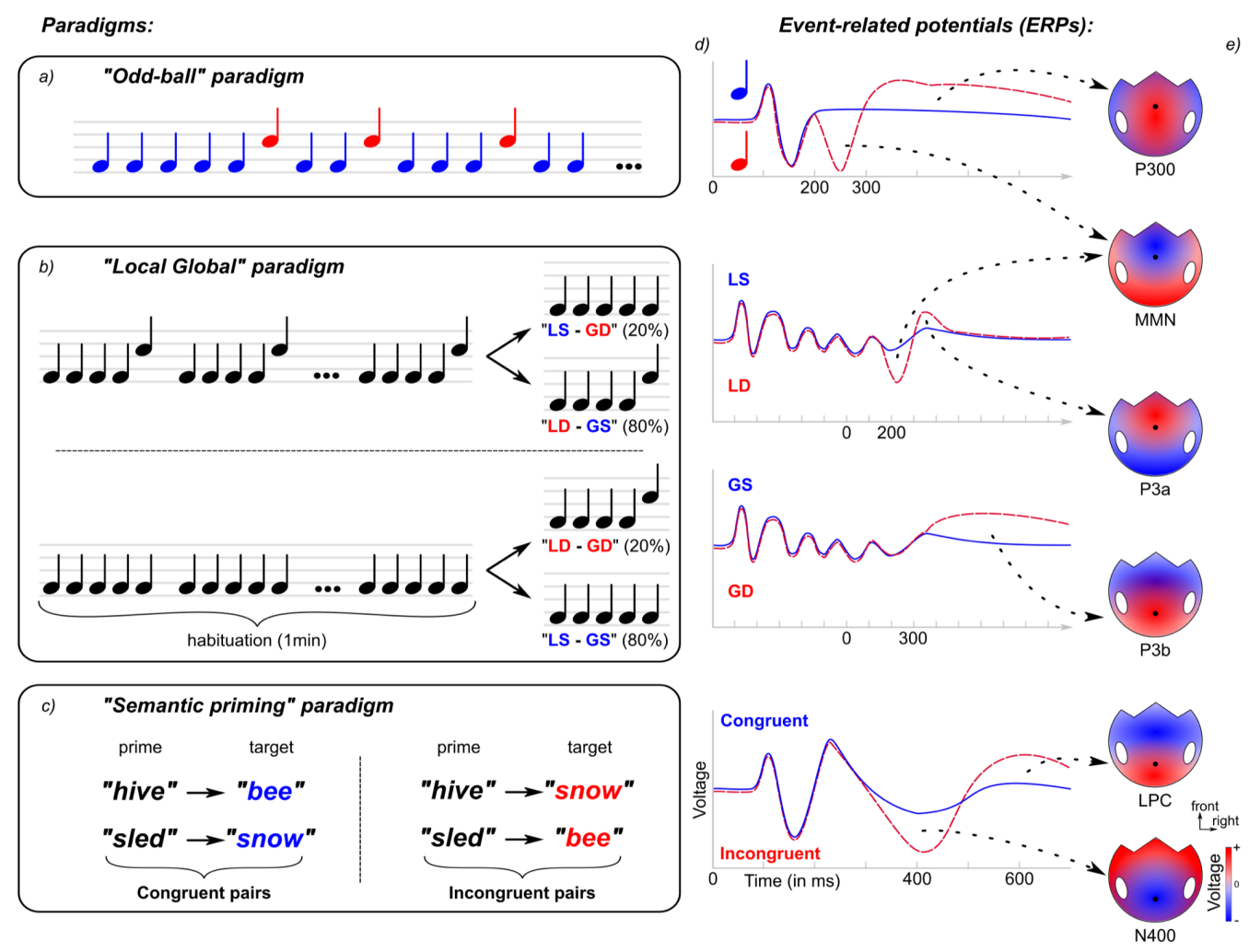

Figure 2: ERPs paradigms and their respective neurophysiological responses. Schematic representation of the "Odd-ball" (a), the "Local Global" (b) and the "'Semantic priming', (c) paradigms. Each paradigm elicits specific event-related potentials (ERPs) displayed across the time form one electrode (d) and as scalp topography of the subtraction (red curve-blue curve) at a specific time (e, the black dot represents the position of the electrode). The "Local Global" paradigm has been designed to disentangle the 2 components of the P300 classically elicited by the "Odd-ball" paradigm: (P3a \& P3b). Note the topography and the temporal relation similarity between MMN/P300 sequence elicited by the "Odd-ball"' and "Local Global" paradigms and the N400/LPC sequence elicited by the semantic paradigm. LS: local standard trial; LD: local deviant trial; GS: global standard trial; GD: global deviant trial. MMN: Mismatch Negativity; LPC Late positive component.

windows remains unchanged. Therefore, the early and unconscious decoding effect seems specific to statistical regularities of the physical stimuli, whereas the late P3b effect seems to reflect a genuine abstract processing of global violations, and the updating of a rule representation in conscious working memory (70).

We close this section by noting the close similarity between neural signatures of conscious access to auditory and to visual stimuli. We previously proposed that this 
similarity, that is contrasting with the differences differentiating early unconscious processing, may reflect a general neural mechanism specific to conscious access irrespective of the sensory modality and of its specific content within the theoretical framework of the Global Neuronal Workspace (71).

\section{Probing semantic processing}

We recently used the very same approach based on this two serial stages (unconscious then conscious) of processing, to test its validity during semantic processing of symbolic verbal stimuli. Since the seminal works and Kutas and colleagues, a N400 ERP component has been discovered as a key marker of verbal semantic processing (72). Since then, a rich literature investigated the precise psychological and neural properties of the N400 and of other correlates of semantic processing such as the late positive complex (LPC, also described as P600) $(73,74)$. Some theorists proposed to link the N400 with a late post-recognition stage of word processing (75), while other models postulated that it reflects an early stage occurring prior to word recognition and semantic access (76).

Several studies have demonstrated that semantic processing can occur unconsciously in conscious subjects. For instance, when using a rapid-serial visual presentation (RSVP) task such as the 'attentional blink' paradigm, subjects failed to report target words, while a N400 signature of verbal semantic processing could still be observed (77). Moreover, similarly to the MMN/P300 sequence we observed for a novel stimulus, while the N400 could occurred in the absence of conscious access to the target word, the later event (P3b) seemed to be observed exclusively when subjects were conscious of this word $(78,53)$. In one masking study, Naccache et al. even revealed a modulation of amygdala activity by the emotional valence of masked 
words in epileptic patients implanted with intracranial electrodes (9). Interestingly, while masked words elicited a single response in the amygdala, consciously perceived unmasked words elicited two successive responses, in agreement with our 2-stage model. In a recent ERP study investigating the semantic integration of multiple words in a visual masking paradigm, we showed that the N400 effects were similar for both masked and unmasked conditions, whereas the LPC/P600 effects were strongly affected by stimulus visibility (79). Such qualitative differences are supporting the hypothesis that while the N400 is a marker of non-conscious semantic processing, the LPC/P600 indexes conscious semantic processing of words. Interestingly, other studies reported the presence of an N400 and the absence of P3b for unconsciously perceived words in the attentional blink paradigm $(53,77)$. In a classical "Semantic priming" paradigm (Fig-2c), we could demonstrate in 2015 that the N400 could be observed both in conscious subjects (controls), and in DOC patients (MCS and VS), but that the LPC/P600 was essentially be present in conscious or MCS patients not in VS patients (32). These results support the generalization of the 2-stage model of perception to semantic processing. While the N400 would index an early, local (verbal semantic network) and unconscious stage of processing (as the MMN-P3a for the processing of auditory novelty), the late, brain-scale and sustained LPC/P600 would index conscious access to semantic knowledge (as the P3b for the processing of novelty). Note that we recently explored conscious and unconscious processing of polysemous words in conscious healthy subjects with both behavioral (priming effects) and ERP data, and observed results supporting this theoretical view (16). 


\section{Clinical implications}

As previously mentioned, diagnosis of consciousness in a non-communicative patient can be very challenging. In this situation, indirect cues collected through functional brain-imaging methods such as neurophysiological tolls we presented above can be very helpful. Indeed, the distinction between VS and MCS patient has an important impact on the prognosis of consciousness recovery $(80,81)$.

Group analysis is valuable in a research setting but for a clinical use, clinicians need reliable individual results. Several concerns have been raised on this specific issue, especially regarding the important variability of the methods across study. Clinicians interpreting these complex analyses must be perfectly aware of the caveats and pitfalls related to the signal processing and the applied statistics they use. This fundamental issue has been specifically assessed for the "Local Global" paradigm $(82,83)$. If the presence of a genuine global effect (in the late temporal window; $>250$ $\mathrm{ms}$ ) is highly predictive of conscious processing (both high specificity and positive predictive value), and can be observed in almost $100 \%$ of conscious controls attending to the stimuli $(25,27,29)$, its absence is more difficult to interpret in patients. Indeed we demonstrated that normal conscious subject engaged in a distractive task requiring attention easily failed to detect global deviant trials (GD) and consequently lose the global effect (25). This means that a conscious patient distracted by any other stimulus and thus not engaged in the task could easily failed this test (both poor sensitivity and poor negative predictive value). Some paradigms very useful in a research setting (group level analysis) are simply not sensitive enough at the individual level to have a real clinical interest. For instance the classical analysis of ERPs evoked by the "Semantic priming" paradigm allow the detection of a N400 or an LPC in only $50 \%$ of healthy volunteers $(84,32)$. 
Finally we would like to emphasize the importance of an individualized neurological approach of any patient, taking into account any possible impairment of the sensorymotor pathway and/or cognitive functions. For instance in the absence of earlyevoked response to sounds (related to the primary auditory cortex), clinician should ensure that the patient is not simply deaf (using for example brainstem auditory evoked potentials) before interpret further the absence of ERPs. In such a case, probing directly EEG signatures of conscious state (patterns of spectral power, functional connectivity or complexity measures) as mentioned in the introduction could be helpful (85).

\section{Conclusion}

In this article, we illustrated how recent advances in cognitive neuroscience enabled to disentangle conscious from unconscious processing stages in normal subjects as well as in non-communicating patients. These two examples emphasize how fruitful is the bidirectional approach exploring cognition in brain-damaged patients as well as in in healthy subjects. This bidirectional strategy enables:

- $\quad$ to observe unexpected results in extreme situations

- to infer theoretical principles that can be verified and tested in healthy controls

- $\quad$ and last but not least to engage into translational efforts aiming at providing the patients with original diagnostic, prognostic and therapeutic tools.

\section{Disclosure of interest}

The authors declare that they have no competing interest. 


\section{Acknowledgements:}

This work was supported by the Amicale des Anciens Internes des Ho^ pitaux de Paris and the Syndicats des Chefs de Cliniques et Assistants des Ho^ pitaux de Paris’” (AAIHP-SCCAHP; BR), the Assistance Public-Ho^ pitaux de Paris (AP-HP; BR), the Philippe Foundation (BR), the James S. McDonnell Foundation (LN), the Acade' mie des Sciences - Grand Prix Lamonica de Neurologie (LN) and by the FRM Equipe 2015 (LN).

\section{References:}

1. Kihlstrom JF. The cognitive unconscious. Science. 1987 Sep 18;237(4821):1445-52.

2. Dehaene S, Naccache L. Towards a cognitive neuroscience of consciousness: basic evidence and a workspace framework. Cognition. 2001 Apr;79(1-2):137.

3. Naccache L. Nouvel inconscient (Le): Freud, le Christophe Colomb des neurosciences. Odile Jacob; 2006. 467 p.

4. Dehaene S, Charles L, King J-R, Marti S. Toward a computational theory of conscious processing. Curr Opin Neurobiol. 2014 Apr;25:76-84.

5. Fodor JA. The modularity of mind: An essay on faculty psychology. MIT press; 1983.

6. Schneider W, Shiffrin RM. Controlled and automatic human information processing: I. Detection, search, and attention. Psychol Rev. 1977;84(1):1.

7. Naccache L. Conscious influences on subliminal cognition exist and are asymmetrical: validation of a double prediction. Conscious Cogn. 2008 Dec;17(4):1359-1360; discussion 1361-1363.

8. Naccache L, Dehaene S. The priming method: imaging unconscious repetition priming reveals an abstract representation of number in the parietal lobes. Cereb Cortex N Y N 1991. 2001 Oct;11(10):966-74.

9. Naccache L, Gaillard R, Adam C, Hasboun D, Clémenceau S, Baulac M, et al. A direct intracranial record of emotions evoked by subliminal words. Proc Natl Acad Sci U S A. 2005 May 24;102(21):7713-7. 
10. Kouider S, Dehaene S. Levels of processing during non-conscious perception: a critical review of visual masking. Philos Trans R Soc Lond B Biol Sci. 2007 May 29;362(1481):857-75.

11. Kentridge RW, Heywood CA, Weiskrantz L. Attention without awareness in blindsight. Proc Biol Sci. 1999 Sep 7;266(1430):1805-11.

12. Naccache L, Blandin E, Dehaene S. Unconscious masked priming depends on temporal attention. Psychol Sci. 2002 Sep;13(5):416-24.

13. Kentridge RW, Nijboer TCW, Heywood CA. Attended but unseen: visual attention is not sufficient for visual awareness. Neuropsychologia. 2008 Feb $12 ; 46(3): 864-9$.

14. Greenwald AG, Abrams RL, Naccache L, Dehaene S. Long-term semantic memory versus contextual memory in unconscious number processing. J Exp Psychol Learn Mem Cogn. 2003 Mar;29(2):235-47.

15. Van Opstal F, Gevers W, Osman M, Verguts T. Unconscious task application. Conscious Cogn. 2010 Dec;19(4):999-1006.

16. Rohaut B, Alario F-X, Meadow J, Cohen L, Naccache L. Unconscious semantic processing of polysemous words is not automatic. Neurosci Conscious. 2016 Jan 1;2016(1):niw010.

17. van Gaal S, Ridderinkhof KR, Fahrenfort JJ, Scholte HS, Lamme VAF. Frontal cortex mediates unconsciously triggered inhibitory control. J Neurosci Off J Soc Neurosci. 2008 Aug 6;28(32):8053-62.

18. van Gaal S, Ridderinkhof KR, van den Wildenberg WPM, Lamme VAF. Dissociating consciousness from inhibitory control: evidence for unconsciously triggered response inhibition in the stop-signal task. J Exp Psychol Hum Percept Perform. 2009 Aug;35(4):1129-39.

19. Reuss H, Desender K, Kiesel A, Kunde W. Unconscious conflicts in unconscious contexts: the role of awareness and timing in flexible conflict adaptation. J Exp Psychol Gen. 2014 Aug;143(4):1701-18.

20. Meijs E, Slagter HA, Lange FP de, Gaal S van. Dynamic interactions between top-down expectations and conscious awareness. bioRxiv. 2017 Jun $16 ; 151019$.

21. Baars BJ. A Cognitive Theory of Consciousness. Cambridge University Press; 1993. $454 \mathrm{p}$.

22. Kotchoubey B, Lang S, Mezger G, Schmalohr D, Schneck M, Semmler A, et al. Information processing in severe disorders of consciousness: vegetative state and minimally conscious state. Clin Neurophysiol Off J Int Fed Clin Neurophysiol. 2005 Oct;116(10):2441-53. 
23. Perrin F, Schnakers C, Schabus M, Degueldre C, Goldman S, Brédart S, et al. Brain response to one's own name in vegetative state, minimally conscious state, and locked-in syndrome. Arch Neurol. 2006 Apr;63(4):562-9.

24. Schnakers C, Perrin F, Schabus M, Majerus S, Ledoux D, Damas P, et al. Voluntary brain processing in disorders of consciousness. Neurology. 2008 Nov 11;71(20):1614-20.

25. Bekinschtein TA, Dehaene S, Rohaut B, Tadel F, Cohen L, Naccache L. Neural signature of the conscious processing of auditory regularities. Proc Natl Acad Sci U S A. 2009 Feb 3;106(5):1672-7.

26. Fischer C, Luaute J, Morlet D. Event-related potentials (MMN and novelty P3) in permanent vegetative or minimally conscious states. Clin Neurophysiol Off J Int Fed Clin Neurophysiol. 2010 Jul;121(7):1032-42.

27. Faugeras F, Rohaut B, Weiss N, Bekinschtein TA, Galanaud D, Puybasset L, et al. Probing consciousness with event-related potentials in the vegetative state. Neurology. 2011 Jul 19;77(3):264-8.

28. Cavinato M, Volpato C, Silvoni S, Sacchetto M, Merico A, Piccione F. Eventrelated brain potential modulation in patients with severe brain damage. Clin Neurophysiol Off J Int Fed Clin Neurophysiol. 2011 Apr;122(4):719-24.

29. Faugeras F, Rohaut B, Weiss N, Bekinschtein T, Galanaud D, Puybasset L, et al. Event related potentials elicited by violations of auditory regularities in patients with impaired consciousness. Neuropsychologia. 2012 Feb;50(3):403-18.

30. Chennu S, Finoia P, Kamau E, Monti MM, Allanson J, Pickard JD, et al. Dissociable endogenous and exogenous attention in disorders of consciousness. NeuroImage Clin. 2013;3:450-61.

31. Risetti M, Formisano R, Toppi J, Quitadamo LR, Bianchi L, Astolfi L, et al. On ERPs detection in disorders of consciousness rehabilitation. Front Hum Neurosci. 2013;7:775.

32. Rohaut B, Faugeras F, Chausson N, King J-R, Karoui IE, Cohen L, et al. Probing ERP correlates of verbal semantic processing in patients with impaired consciousness. Neuropsychologia. 2015 Jan;66:279-92.

33. Gibson RM, Chennu S, Fernández-Espejo D, Naci L, Owen AM, Cruse D. Somatosensory attention identifies both overt and covert awareness in disorders of consciousness. Ann Neurol. 2016 juillet;n/a-n/a.

34. Sergent C, Faugeras F, Rohaut B, Perrin F, Valente M, Tallon-Baudry C, et al. Multidimensional cognitive evaluation of patients with disorders of consciousness using EEG: A proof of concept study. NeuroImage Clin. 2017;13:455-69. 
35. Goldfine AM, Victor JD, Conte MM, Bardin JC, Schiff ND. Determination of awareness in patients with severe brain injury using EEG power spectral analysis. Clin Neurophysiol. 2011 Nov 1;122(11):2157-68.

36. Supp GG, Siegel M, Hipp JF, Engel AK. Cortical Hypersynchrony Predicts Breakdown of Sensory Processing during Loss of Consciousness. Curr Biol. 2011 Dec 6;21(23):1988-93.

37. King J-R, Sitt JD, Faugeras F, Rohaut B, El Karoui I, Cohen L, et al. Information sharing in the brain indexes consciousness in noncommunicative patients. Curr Biol CB. 2013 Oct 7;23(19):1914-9.

38. Sitt JD, King J-R, El Karoui I, Rohaut B, Faugeras F, Gramfort A, et al. Large scale screening of neural signatures of consciousness in patients in a vegetative or minimally conscious state. Brain J Neurol. 2014 Aug;137(Pt 8):2258-70.

39. Claassen J, Velazquez A, Meyers E, Witsch J, Falo MC, Park S, et al. Bedside quantitative electroencephalography improves assessment of consciousness in comatose subarachnoid hemorrhage patients. Ann Neurol. 2016 Jul 29;

40. Chennu S, Annen J, Wannez S, Thibaut A, Chatelle C, Cassol H, et al. Brain networks predict metabolism, diagnosis and prognosis at the bedside in disorders of consciousness. Brain J Neurol. 2017 Jun 27;

41. Ragazzoni A, Cincotta M, Giovannelli F, Cruse D, Young GB, Miniussi C, et al. Clinical neurophysiology of prolonged disorders of consciousness: From diagnostic stimulation to therapeutic neuromodulation. Clin Neurophysiol. 2017 Sep 1;128(9):1629-46.

42. Plum F, Posner JB. The Diagnosis of Stupor and Coma. 3rd edn. Philadelphia: Oxford University Press; 1980. 398 p.

43. Giacino JT, Kalmar K, Whyte J. The JFK Coma Recovery Scale-Revised: measurement characteristics and diagnostic utility. Arch Phys Med Rehabil. 2004 Dec;85(12):2020-9.

44. Kondziella D, Friberg CK, Frokjaer VG, Fabricius M, Møller K. Preserved consciousness in vegetative and minimal conscious states: systematic review and meta-analysis. J Neurol Neurosurg Psychiatry. 2015 Jul 2;jnnp-2015310958.

45. Owen AM, Coleman MR, Boly M, Davis MH, Laureys S, Pickard JD. Detecting awareness in the vegetative state. Science. 2006 Sep 8;313(5792):1402.

46. Naccache L. Psychology. Is she conscious? Science. 2006 Sep 8;313(5792):1395-6.

47. Monti MM, Vanhaudenhuyse A, Coleman MR, Boly M, Pickard JD, Tshibanda L, et al. Willful modulation of brain activity in disorders of consciousness. $\mathrm{N}$ Engl J Med. 2010 Feb 18;362(7):579-89. 
48. Ulanovsky N, Las L, Nelken I. Processing of low-probability sounds by cortical neurons. Nat Neurosci. 2003 Apr;6(4):391-8.

49. Sutton S, Braren M, Zubin J, John ER. Evoked-potential correlates of stimulus uncertainty. Science. 1965 Nov 26;150(3700):1187-8.

50. Squires NK, Squires KC, Hillyard SA. Two varieties of long-latency positive waves evoked by unpredictable auditory stimuli in man. Electroencephalogr Clin Neurophysiol. 1975 Apr;38(4):387-401.

51. Näätänen R, Tervaniemi M, Sussman E, Paavilainen P, Winkler I. "Primitive intelligence" in the auditory cortex. Trends Neurosci. 2001 May;24(5):283-8.

52. Donchin E, Coles MG. Is the P300 component a manifestation of context updating. Behav Brain Sci. 1988;11(3):357-427.

53. Sergent C, Baillet S, Dehaene S. Timing of the brain events underlying access to consciousness during the attentional blink. Nat Neurosci. 2005 Oct;8(10):1391-400.

54. Pegado F, Bekinschtein T, Chausson N, Dehaene S, Cohen L, Naccache L. Probing the lifetimes of auditory novelty detection processes. Neuropsychologia. 2010 Aug;48(10):3145-54.

55. Wetter S, Polich J, Murphy C. Olfactory, auditory, and visual ERPs from single trials: no evidence for habituation. Int J Psychophysiol Off J Int Organ Psychophysiol. 2004 Nov;54(3):263-72.

56. Mäntysalo S, Näätänen R. The duration of a neuronal trace of an auditory stimulus as indicated by event-related potentials. Biol Psychol. 1987 Jun;24(3):183-95.

57. Lu Z-L, Neuse J, Madigan S, Dosher BA. Fast decay of iconic memory in observers with mild cognitive impairments. Proc Natl Acad Sci U S A. 2005 Feb 1;102(5):1797-802.

58. Sperling G. The information available in brief visual presentations. Psychol Monogr Gen Appl. 1960;74(11):1.

59. Atienza M, Cantero JL, Gómez CM. The mismatch negativity component reveals the sensory memory during REM sleep in humans. Neurosci Lett. 1997 Nov 14;237(1):21-4.

60. Heinke W, Kenntner R, Gunter TC, Sammler D, Olthoff D, Koelsch S. Sequential effects of increasing propofol sedation on frontal and temporal cortices as indexed by auditory event-related potentials. Anesthesiology. 2004 Mar;100(3):617-25.

61. Kane NM, Curry SH, Butler SR, Cummins BH. Electrophysiological indicator of awakening from coma. Lancet. 1993 Mar 13;341(8846):688. 
62. Fischer C, Morlet D, Bouchet P, Luaute J, Jourdan C, Salord F. Mismatch negativity and late auditory evoked potentials in comatose patients. Clin Neurophysiol. 1999 Sep 1;110(9):1601-10.

63. Naccache L, Puybasset L, Gaillard R, Serve E, Willer J-C. Auditory mismatch negativity is a good predictor of awakening in comatose patients: a fast and reliable procedure. Clin Neurophysiol Off J Int Fed Clin Neurophysiol. 2005 Apr;116(4):988-9.

64. Wijnen VJM, van Boxtel GJM, Eilander HJ, de Gelder B. Mismatch negativity predicts recovery from the vegetative state. Clin Neurophysiol Off J Int Fed Clin Neurophysiol. 2007 Mar;118(3):597-605.

65. Brázdil M, Rektor I, Daniel P, Dufek M, Jurák P. Intracerebral event-related potentials to subthreshold target stimuli. Clin Neurophysiol Off J Int Fed Clin Neurophysiol. 2001 Apr;112(4):650-61.

66. Bernat E, Bunce S, Shevrin H. Event-related brain potentials differentiate positive and negative mood adjectives during both supraliminal and subliminal visual processing. Int J Psychophysiol. 2001;42(1):11-34.

67. Del Cul A, Baillet S, Dehaene S. Brain dynamics underlying the nonlinear threshold for access to consciousness. PLoS Biol. 2007 0ct;5(10):e260.

68. Tzovara A, Simonin A, Oddo M, Rossetti AO, Lucia MD. Neural detection of complex sound sequences in the absence of consciousness. Brain J Neurol. 2015 May 1;138(5):1160-6.

69. King JR, Faugeras F, Gramfort A, Schurger A, El Karoui I, Sitt JD, et al. Singletrial decoding of auditory novelty responses facilitates the detection of residual consciousness. NeuroImage. 2013 Dec;83:726-38.

70. Naccache L, King J-R, Sitt J, Engemann D, El Karoui I, Rohaut B, et al. Neural detection of complex sound sequences or of statistical regularities in the absence of consciousness? Brain. 2015 Dec;138(Pt 12):e395.

71. El Karoui I, King J-R, Sitt J, Meyniel F, Van Gaal S, Hasboun D, et al. EventRelated Potential, Time-frequency, and Functional Connectivity Facets of Local and Global Auditory Novelty Processing: An Intracranial Study in Humans. Cereb Cortex. 2015 Nov 1;25(11):4203-12.

72. Kutas M, Hillyard SA. Reading senseless sentences: brain potentials reflect semantic incongruity. Science. 1980;207(4427):203-5.

73. Pulvermüller F, Shtyrov Y, Hauk O. Understanding in an instant: neurophysiological evidence for mechanistic language circuits in the brain. Brain Lang. 2009 Aug;110(2):81-94.

74. Kutas M, Federmeier KD. Thirty years and counting: finding meaning in the N400 component of the event-related brain potential (ERP). Annu Rev Psychol. 2011;62:621-47. 
75. Brown C, Hagoort P. The processing nature of the $n 400$ : evidence from masked priming. J Cogn Neurosci. 1993;5(1):34-44.

76. Deacon D, Grose-Fifer J, Hewitt S, Nagata M, Shelley-Tremblay J, Yang C-M. Physiological evidence that a masked unrelated intervening item disrupts semantic priming: implications for theories of semantic representation and retrieval models of semantic priming. Brain Lang. 2004 Apr;89(1):38-46.

77. Luck SJ, Vogel EK, Shapiro KL. Word meanings can be accessed but not reported during the attentional blink. Nature. 1996 Oct 17;383(6601):616-8.

78. Kiefer M. The N400 is modulated by unconsciously perceived masked words: further evidence for an automatic spreading activation account of N400 priming effects. Brain Res Cogn Brain Res. 2002 Feb;13(1):27-39.

79. van Gaal S, Naccache L, Meuwese JDI, van Loon AM, Leighton AH, Cohen L, et al. Can the meaning of multiple words be integrated unconsciously? Philos Trans R Soc Lond B Biol Sci. 2014 May 5;369(1641):20130212.

80. Luauté J, Maucort-Boulch D, Tell L, Quelard F, Sarraf T, Iwaz J, et al. Longterm outcomes of chronic minimally conscious and vegetative states. Neurology. 2010 Jul 20;75(3):246-52.

81. Noé E, Olaya J, Navarro MD, Noguera P, Colomer C, García-Panach J, et al. Behavioral recovery in disorders of consciousness: a prospective study with the Spanish version of the Coma Recovery Scale-Revised. Arch Phys Med Rehabil. 2012 Mar;93(3):428-433.e12.

82. Gabriel D, Muzard E, Henriques J, Mignot C, Pazart L, André-Obadia N, et al. Replicability and impact of statistics in the detection of neural responses of consciousness. Brain. 2016 Jun 1;139(6):e30-e30.

83. Naccache L, Sitt J, King J-R, Rohaut B, Faugeras F, Chennu S, et al. Reply: Replicability and impact of statistics in the detection of neural responses of consciousness. Brain. 2016 Jun;139(Pt 6):e31.

84. Cruse D, Beukema S, Chennu S, Malins JG, Owen AM, McRae K. The reliability of the N400 in single subjects: Implications for patients with disorders of consciousness. NeuroImage Clin. 2014;4:788-99.

85. Rohaut B, Raimondo F, Galanaud D, Valente M, Sitt JD, Naccache L. Probing consciousness in a sensory-disconnected paralyzed patient. Brain Inj. 2017 Jun 28;0(0):1-6.

86. Laureys $\mathrm{S}$. The neural correlate of (un)awareness: lessons from the vegetative state. Trends Cogn Sci. 2005 Dec;9(12):556-9. 